\title{
Value of an Encounter from an Ethical Perspective
}

Krystyna Najder-Stefaniak (Warsaw University of Life Sciences; Warszawa, Poland)

\section{Ethos as a Human Dwelling Place}

When ethical reflection appeared in philosophy, it was directed at discovering truths that would enable human beings to take care of themselves in a sensible way. Such care neither hindered cheerfulness nor was based on dictates and prohibitions. It assumed the value of life understood as active, subjective existence in the context of an intelligible world. It was both an obligation and a life strategy, combining the perspectives of truth and goodness. Life inspired by the ancient concept of care was supposed to advance the "development of the art of being."

This art of being should consider the fact that humans can exist, live, act, and adopt specific forms and meanings only within the surroundings with which they interact. These interactions ought to become an object of ethical consideration. Humans influence their surroundings, and by changing them they gain new challenges and inspirations, which in turn can lead to the discovery of new possibilities for existence for both people and the system in which their surroundings are ordered.

If we, after Heidegger, follow the etymology of the word "ethos," which is the basis of the term introduced by Aristotle, we would learn that "Ethos means abode, dwelling place. The word names the open region in which man dwells. [...] The designation reflects on this dwelling" (Heidegger 1977, 118119). In the original sense, ethos was the name of the place where "a plant grows without obstacles, where it can live and fructify" (Tischner 1982, 53). In order for human beings to "bear [their] own fruit," they must first find the right ethos, namely one's environment, "home," or sphere of life as the space that facilitates understanding, making choices, and acting.

An inhabited area can be opened up through meetings convened by people. Thus, an encounter constitutes a crucial element of ethos. It adds human character to one's surroundings and allows it to vibrate with life. Direct encounters with someone or something appearing in the human surroundings exist, with indirect encounters occurring through traces of some activity.

The notion of "traces" comes from ontology and points to the existence of something not immediately accessible to us. It refers to what is missing here and now, and it inspires us to transcend the present situation. It suggests the 
existence of a reality different from the one we are currently in. Thus, the notion of traces may contain depths from which it is worth learning.

On account of our ability to notice and recognize traces, journeys broaden the mind and store knowledge of epochs and people in books and works of art. Additionally, this ability is beneficial for our safety, enabling us, for example, to anticipate the possibility of coming across predators. Traces are handy in finding water, following the way to a settlement, or in hunting. There are also traces left by experience in our memory; they affect how we think, value, and act. In Trace and Presence Barbara Skarga says "The whole history is nothing else than reading traces. What is science if not an attempt to reveal the sources of phenomena that left traces in observable events? Everything is a trace of what has passed; everywhere we are faced with traces, since presence escapes cognition" (Skarga 2002, 73). Traces are a form of presence in the sense of the French être présents, or being present. Due to the traces left by some being, it can be-to some extent-available even after it has disappeared in the sense of il y a, or being in some place.

In order to use traces, one needs to be aware of the continuity of time and be able to move in its three dimensions. A trace relates to a past presence; it allows us to reveal the past. It also helps us to discover the prerequisites or possibilities for events and encounters that might occur. In this sense, a trace affects the shape of the future. It exists because of the links between the present, the past, and the future. Traces can be found in architecture, books, music, clothes, habits, principles of co-existence, festivals, and poetry. We become parts of the living system by depicting traces that constitute it, and we find how essential it is to our identity. Through encounters we build our cultural identity. As embodied beings, rooted in our environment, we become strong and gain a sense of security, which allows us to meet and dialogue with other cultures, to become hospitable, and to creatively influence the fate of our own culture.

The ability to realize encounters is very important in the art of being. Through direct and indirect meetings we become aware of our surroundings. They help us to discover our own possibilities for being. They open up our dwelling place.

\section{Types of Encounters}

For an encounter to happen, the existence of difference is necessary; it is not, however, sufficient. Pluralism does not always enhance the possibilities offered by an encounter with otherness. This can be easily understood by thinking of relationships in terms of an ecosystem paradigm. However, understanding may not be reached when we perceive relationships in the subject-object scheme. Jean-François Lyotard, a promoter of pluralism, suggested that consensus be replaced with "justice," which centers our attention on "speaking 
out." Understood in this way, however, justice does not yet guarantee that the encounter will take place since this requires listening intently to a variety of opinions. Furthermore, the greatest danger to diversity is the atomization of differences, which leads some to reject the universalism that serves as a point of reference for those seeking truth.

Depending on the perception of difference, we tend to contravene various types of encounters. Comprehension of difference is conditioned by our scheme of reasoning, which can be antagonistic, complementary, dialectic, or synergistic.

Antagonistic thinking is reflected in the "either-or" approach. In this scheme, we assume that difference disqualifies or devalues diverging perspectives. As a result, we either reject difference and defend our own position or become fascinated with diversity, accepting it at the cost of our otherness. In neither case is the encounter enriching; it can only change us. Antagonistic thinking leads to competitive or hostile encounters. In contrast, complementary thinking can result in "supplementary" encounters, where the outcome is a combination of what the parties bring to the situation.

Dialectical processes lead to a synthesis from thesis and antithesis. It produces encounters of a "common sense of loss." Such an encounter permits a going beyond the level of thesis and antithesis, to the discovery of dialectic synthesis. In searching for synthesis, a dialectic encounter advances development and is characterized by open reasoning. Synthesis enriches the thesis by exploiting its potential.

Another outcome of the encounter with difference can be achieved via synergistic thinking. It facilitates a move to the level of meta-reflection, helping us to reveal and understand the conditioning of the otherness of both ourselves and what we come across. Synergistic thinking helps us to recognize and better comprehend the implications of difference and allows for creative activity. It lies at the foundation of culture and civilization. In synergistic encounters we can transcend the borders of our own identity without forsaking it. The encounters based on synergistic thinking enrich our otherness without jeopardizing it with uniformity or conflict.

Synergistic thinking requires respect for the otherness of those we meet, as well as an interest in the truth established by them (emet) and disclosed by them (aletheia). It involves ideas not yet set definitionally. Conflict inevitably results from the juxtaposition of terms referring to the same object with imposed closed meanings suggesting various interpretations.

Difference includes a whole range of characteristics that potentially distinguish, antagonize, justify falsehoods and errors, and enrich encounters. It does not determine the outcome definitively; it is we who decide how difference is handled. Thus, it can be a source of antagonism, conflict, aggression, and destruction. How can we prevent the disruptive effects of difference? Justice, in the sense proposed by Lyotard, may presuppose indifference that results in justification of evil and error. An Aristotelian middle ground between antagonism and indifference could be identified as "hospitality." Hospitality 
allows us to sincerely play host to guests in our home without allowing them to vandalize it. A hospitable encounter supports a deeper, wiser understanding of both what is ours and what we identify with, as well as what is different and what we are hospitably open to. Both parties benefit from this type of the encounter. The guests too, entering into "our otherness" without the intention of destroying it, can begin a dialogue with it.

\section{Value of Dialogue}

The value of dialogue has been unfolded by various philosophers. The oldest paradigm, proposed by Socrates, ordered the course of encounters to better arrive at truth. In his framework for encounters, Socrates provided that they initiate the search for truth without necessarily leading to a final conclusion enclosed within what we have revealed, named, or defined. This scheme of encounter managed to protect cognition from stagnating under the influence of rigid definitions; it maintained the balance between the two types of truth: emet and aletheia. From an ethical perspective, both notions of truth are valuable not so much because they provide us with knowledge, but because they make people realize their ignorance and inspire them to look for the truth.

Martin Buber's writing about encounters is particularly interesting here from the perspective of ethics. He observed that human life is led among objects and other people. It means experiencing the otherness we feel in bodies and things and that we witness in someone else. However, the difference between experiencing objects (bodies and things) and experiencing subjects (other people) is significant. An object meets another object, but objects do not cross their borders (for Buber, each object remains an "it"). In contrast, "I" and "You" function as subjects in the encounter; they do not border anything, for they exist in a relationship (Buber 1974, 292). In Buber's concept of encounters we can find inspiration to realize how great an influence we can have on both the process and effects of our encounters with otherness.

Buber distinguished three spheres in which humans encounter the world. In the first, the "technical," the relation of existential-objective "I-it" takes place. The second is seen as a disguised monologue: "You" is brought to "I" and the "encountered" subject is treated as an aspect of one's own ego. Buber deems the third way in which a person encounters the world as the genuine dialogue. Here we have the direct, encounter I-You, which is anti-instrumental

In the technical approach we face the modern subject-object paradigm. These relations are linear and unilateral. Here it is the "I" that is active. It influences even the perception of "it" as an object to exploit. The existentialobjective attitude adopted in the "technical" perspective excludes dialogue. Similarly, the disguised monologue does not provide any chance for dialogue: "I" is so self-oriented that it fails to perceive anything apart from itself. It is unable to dialogue with any "You." 
According to Buber, participants in dialogue must engage authentically-i.e., they must reveal to one another the entire truth of their existence. The successful dialogue requires of them a sufficient degree of involvement in the encounter. They must be sincere and open. The proper starting point is not a priori agreement with the interlocutor, but acceptance of her otherness. Instead of being threating, otherness begins to arouse interest. Buber's notion of dialogue aims to give encounters the potential for discovering truth-the emet of "You." This begs the question of whether such encounters can happen by means of "traces" left by a "You."

According to Emmanuel Levinas's interpretation, engaging in a dialogical encounter means entering an ethical sphere. In the beginning, he understood this to include liberation from loneliness, though ultimately he suggested that it involved an "opening to infinity." The Other leaves a trace in the encountered. Never is the encounter with the Other neutral. It always has a meaning: it can produce goodness and truth, it calls for responsibility towards and for the Other, and it provides the chance to discover oneself. The "face" of the Other is the key to the infinite. It shows the trace of God. For Levinas, the encounter with the other becomes an ethical and religious act. By directing individuals towards transcendence, it creates their bond with both people and God.

The meeting with the Other is neither easy nor automatic. It presupposes will and effort, which not everyone is able to undertake. According to Levinas, the encounter with others always takes place in an ethical dimension. In the dialogical encounter one learns being towards others to discover oneself. Dialogue is, thus, an ethical relation.

Levinas, who experienced the birth of two totalitarian systemscommunism and fascism-remarked that members of mass societies are characterized by anonymity and the lack of social bonds. These features trigger indifference towards the other that results in helplessness in people and a susceptibility to evil. Levinas's call for the recognition of the other's face in order for there to be an encounter in which dialogue enables one to bear responsibility suggests how to avoid the pitfalls of the human-unfriendly atomized sphere, how to break with selfishness and indifference, and how to protect oneself from the temptation to disconnect and become isolated.

The ethical value of dialogue was presented differently by Józef Tischner, whose philosophy of dialogue is often called the philosophy of drama. It sees the beginning of the entire enterprise of the philosophical search in interpersonal dialogue. Tischner points to two kinds of relationships: that existing between humans and the world, and that between people. There is a difference between how humans approach the world (the scene) and other people. When describing the human-world relation, Tischner sees the space of human life as the scene in which the drama of everyday struggles with the world is played out. In the case of the relationship between human beings, he 
emphasizes dialogical reciprocity. In the dialogical relationship, the "Asker" and the "Asked" stand face to face. The former makes the latter a participant in the situation. A human can surely be treated as an element of the scene, but then an encounter in the relation of human-human cannot occur.

Tischner's interpretation of the encounter discovers the Asker who expects an answer. Awareness of the necessity to provide an answer enables us to feel the presence of other people (Tischner 1982, 12-21). In the encounter one learns that there is also another world apart from one's own-the world of the other. Thus, the encounter induces thinking. Moreover, it has an agathological dimension; it is an ethical situation, the primary source of an ethical experience.

\section{Encounter in the Ecosystem Paradigm}

In the new paradigm of reasoning inspired by environmentalism, a human being is perceived as an element of functional systems constituted by relationships. The modern scheme of thinking about relationships (subjectobject) is being supplanted by the ecosystem paradigm. The meaning of this new approach for the development of contemporary perception and interpretation of reality was emphasized by historian and sociologist Edgar Morin, who explored the origins of ecological awareness that changes our world view. He points to what he sees as the fundamental conclusion of one of the pioneers of biological revolution, Erwin Schrodinger: ecosystems coorganize and participate in programming the organisms that belong to them (Morin 1977, 46). Morin, accentuating the theoretical outcomes of this assumption as extraordinarily significant, writes: "The ecosystem relationship is not an external relation of two closed beings, but an interactive correlation between two open systems, each constituting both a whole and a part of the other one" (Morin 1977, 46). Morin appreciates the consequences of the introduction of a new scheme of relationships based on the ecosystem paradigm. Here the account of relationships differs from the unilateral, linear subject-object relationship that has framed understandings in modern science. In the linear, unilateral scheme of interdependencies the notion of determinacy, contrasted with the sovereignty of the subject, is crucial. Thus, the disjunction of "either freedom or determinacy" becomes obvious, and concern for subjectivity begins to be identified with avoiding any determinants. Modern, autonomous human beings withdraw into themselves in order to be free. They do not notice that encounters with others could broaden the range of possibilities, thus making them freer.

The modern paradigm contains another trap. By stressing human subjectivity in the subject-object framework, contemporary humanism simultaneously involves the threat of objectifying people. Thinking in accordance with this paradigm implies seeing others and even ourselves as 
objects of our acts and consideration. It is not then difficult to treat an objectified other, or even ourselves, as a means to our ends, contrary to Immanuel Kant's requirement.

The ecosystem paradigm thus allows us to avoid identified modern dangers. Humans want to enter relationships in order to discover possibilities in their surroundings and their own potential for activity. In such relationships they do not feel threatened by the deprivation of subjectivity or by the deficit of freedom. They appreciate the value of encounters and of togetherness, as opposed to living in separation from others. When alienated, we do not become a part of the whole that could be an enriching part of us.

Were we to see relationships in keeping with the ecosystem paradigm, causality would no longer be linear and one-sided; we would become capable of finding new aspects of human interdependencies and of understanding our relationship with, and links to, the environment, conversely to the modern paradigm. This new understanding implies a sense of responsibility bound to the awareness that our "gestalt" and that of others is affected by our activities and through the construction of the environment and interactions we initiate.

Reflections on our surroundings trigger the recognition of their two dimensions: the first might be called the "environment," the second "space." The former refers to the objective existence of our surroundings, whereas "space" indicates the way it is imagined, perceived, and experienced through the schemes of reasoning and valuing. Both of these notions aid in our comprehension of the human situation and our recognition of the relationships in which we are involved. They imply an understanding of human beings in their physical and spiritual dimensions, inducing considerations of the relationships between these dimensions.

What surrounds us is essential as it encourages or provokes us to respond to opportunities that it creates. It impacts what we can achieve in our human potentiality, but it does not automatically determine us. Human beings take advantage of the chances offered by our surroundings according to our will and ability. We are, after all, ethical subjects-i.e., "relatively isolated systems" - with inner centers of activity. ${ }^{1}$ We are responsible ${ }^{2}$ for the outcomes

${ }^{1}$ Roman Ingarden introduced the notion of "system" to reflections on responsibility. The idea of relatively isolated systems proved advantageous in the discussion concerning conditions that must be fulfilled by a subject of responsibility. The basic requirement to become a subject of responsibility is having "a centre of action that enables [us] to [...] undertake initiative." According to Ingarden, "an acting person (an entity that constitutes unity together with the body) must form a system relatively isolated, a system of a quite particular kind, one that is not possible in lifeless things and cannot even realize itself in all living beings" (See: Ingarden 1972, 133-134).

2 It is worth distinguishing between "responsibility for" and "responsibility towards." The former can be understood as the awareness that our activities have effects and that we create them even when we do not realize it. "Responsibility towards" comes as a result of our obligations towards the environment. 
of what we do, or leave undone. The scope of human responsibility is apparent in light of our ability to change, choose, construct consciously, and even create our surroundings. We change the environment by determining what is external to us, while we modify the space in two ways: by developing or destroying our ability to perceive and understand the environment, and by altering it. The shape of the space greatly depends on our human capabilities and cognitive skills.

Before we can state that human beings can be creative in the area set by the value of truth, and that we are capable of creative reflection, we must think more carefully about basic understandings of the connection between reality and its representations-environment and human space-which can be boiled down to a confrontation between "original" and "copy." We need to realize that representation is not a mere copy of existence. It establishes itself within the framework of reasoning of which it is a part. Creative thinking initiates new systems of understanding that enable new possibilities of perception to be realized. Consequently, we discover new aspects of the manifestations of reality, are encouraged to raise new questions, and while searching for answers we can initiate new phenomena of being. In this context, it becomes imperative to ask: "How should it be?"; a praxeological perspective ought to be complemented with an ethical one. An ethics of creativity that looks for universal axiological truths is necessary, enabling us to verify values proposed by further systems of the profane. The universal axiological truths discovered in synergistic thinking, at the meta-level of diverse actualized systems of being, allow us to notice goals other than those implied by these systems. As a result, they are indispensable for people to be able and willing to act innovatively.

While preparing to creatively exist in the world, we must facilitate comprehensive human development that is versatile enough to enable us to have synergistic encounters and experiences of the enchantment of the world. Through disenchantment we had reduced the world to its current character of the profane and we had disconnected it from mystery and transcendence. The transcendent dimension is essential for thinking about the possibility of going beyond the borders of the here and now. In order to handle life creatively, modern people should "break the spell" that fossilizes the world and humans in their current form and replace it with enchantment inducing the search for truth that has not yet been "touched" In contrast to the epistemologically dominant ocular-centric metaphor in which clear vision is linked with knowledge, the metaphor of "touch" is helpful here for thinking about cognition. We owe it to physicists who acknowledge that the truths revealed by their research are responses to a way of touching reality, which corresponds well with reflections concerning human creative skills. It helps to recognize that people can be creative also in the sphere of cognitive activity. We must be able to use our creative capacities when looking for both ethical and 
praxeological dimensions of our space, and to realize its openness actualized through encounters with otherness.

\section{References}

Buber, M. 1974. “Słowa-Zasady [Words-Rules]”. Znak 3 (237): 291-310.

Heidegger, M. 1977. "Letter on Humanism”. In Building Dwelling Thinking. Selected Essays. Warsaw: Czytelnik Publishing House. von Hildebrand, D., Kłoczowski, J.A., \& Paściak J. (Eds.). 1982, Wobec wartości [Facing values]. Poznań: W Drodze Publishing House.

Ingarden, R. 1972. “O odpowiedzialności i jej podstawach ontycznych [On Responsibility: Its Ontic Foundations]”. In Książeczka o człowieku [Little Book About Man]. Cracow: Literary Press: 133-134.

Morin, E. 1977. Zaginiony paradygmat - natura ludzka [The Lost Paradigm: Human Nature]. Warsaw: PIW.

Skarga, B. 2002. Ślad i obecność [Trace and Presence]. Warsaw: Polish Scientific Publishers PWN.

Tischner, J. 1982. "Etyka wartości i nadziei [The Ethics of Values and Hope]". In von Hildebrand, D., Kłoczowski, J.A., \& PaściaK, J. (Eds.), Wobec wartości [Facing Values]. Poznań: W Drodze Publishing House. 
Krystyna Najder-Stefaniak (Warsaw University of Life Sciences)

\title{
Value of an encounter from an ethical perspective
}

\begin{abstract}
This article investigates the relationship between the possibilities of actualizing our encounters and the openness of human space. It describes various types of encounters and shows the correlations between the perception of difference and the inclination to contravene certain encounters. The effects of encounters based on antagonistic, complementary, dialectic, and synergistic thinking are explored in a way that helps to better understand the aims and consequences of encounters actualized in diverse frameworks of dialogue. Further, the impact of paradigms of reasoning on how the value of meetings is understood is described. The results of the modern perception of relationships in the subject-object scheme and in the ecosystem paradigm are presented. The latter allows for recognition that encounters can facilitate creative activity by expanding human space.
\end{abstract}

Keywords: Antagonistic encounter, complementary encounter, dialectic encounter, difference, ethos, synergistic encounter

Ethics in Progress (ISSN 2084-9257). Vol. 5 (2014). No. 1. pp. 113-122.

doi:10.14746/eip.2014.1.7 